\title{
Do actual medical literature depict a satisfactory view of Left Ventricular assistant device and Right Ventricular failure?
}

\author{
Elio Aloia $^{1 *}$, Matteo Cameli ${ }^{1}$, Aleksander Dokollari ${ }^{2}$, Gianluigi Buccoliero ${ }^{1}$, Mario Stricagnoli ${ }^{1}$, Cosimo \\ Rizzo $^{1}$, Giulia Elena Mandoli ${ }^{1}$, Aladino Ibrahim ${ }^{1}$, Massimo Maccherini ${ }^{2}$ and Sergio Mondillo ${ }^{1}$ \\ 1Department of Medical Biotechnologies, Division of Cardiology, University of Siena, Siena, Italy \\ 2Department of Cardiac Surgery, University of Siena, Siena, Italy
}

\begin{abstract}
Background: Incidence and prevalence of heart failure are rising up. In patients with advanced heart failure (AHF), Left Ventricular (LV) assist devices (LVADs) are an increasingly common therapy for AHF. Right ventricular failure (RVF) and device related issues make this therapy a challenge to apply to a broader population. On the other hand, RVF, after LVAD implantation, is associated with an increased incidence of peri-operative mortality, prolonged length of stay and worst survival. Waiting for a randomized multicentre study, we just have to rely on clinical judgment of multidisciplinary experts, so the main goal of this review is to find out the relationship among LVAD and RVF.

Methods: We performed a meticulous online research on pubmed looking for the lateststudies on LVAD and BiVAD implantation, predictors of RVF and patients selectioncriteria in way to relate these variables with clinical outcomes.

Results: many studies were not randomized nor stratificated and there was aninhomogenity in the definition of RVF. In addition, no single variable adequately discriminates or is reliable for patient selection and BiVAD selection criteria were subjective and not objective in many cases.

Conclusions: We are far from a completely and clear knowledge about the prognosis of our patients It is time to find out new methods of evaluations in way to forsee RVF in patients that are going to be implanted with LVAD or BiVAD. Furthermore, new patients selection criteria must be established in way to overcome the increasing rate of RVF in implanted patients.
\end{abstract}

Accepted on March 29, 2017

\section{Advanced Heart Failure, LVAD and RVF. What's the Problem?}

Here and now incidence and prevalence of heart failure are rising up [1]. In addition disabling symptoms, improving quality of life and prognosis are fundamental clues to all successful therapies for the treatment of advanced heart failure. Left ventricular (LV) assist devices (LVADs) are an increasingly common therapy for advanced heart failure [2].

The REMATCH clinical trial was the first clinical study to randomly assign patients ineligible for transplantation (destination therapy) to either continued optimal medical therapy or electronically driven LVAD therapy. The trial revealed a significant survival benefit of LVAD therapy at 12 months compared with medical therapy alone (52\% vs $25 \%$, respectively) [3].Subsequent studies have demonstrated further improvements in survival, device durability and patient satisfaction parameters for both destination therapy and bridgeto-transplantation indications $[4,5]$.

The most common indications include
1. Bridge to transplant (BTT) [6].

2. Bridge to candidacy (BTC): $[7,8]$.

3. Destination therapy (DT): [9]. The average length of LVAD support for BTT indication ranges from weeks to years and generally months to years for DT indication [10-13].

4. Bridge to recovery (BTR).

Scientific and technological ameliorations of LVAD implantation as well as perioperative medical management lead to a significant reduction in complication rates, an improved survival and better quality of life: all leading to outcomes approaching those achieved with heart transplant [14-19]. As a matter of fact, 1 -year post implant survival is about $80 \%$ with a continuous flow LVAD (CF-LVAD) [20].

Amazing technological outcomes made the LVAD an outstanding option as destination therapy (DT) [16,21]. Currently, $40 \%$ of the LVADs are implanted as DT [20] because of an improved exercise tolerance and end-organ dysfunction [22]. 
Survival at 1 and 2 years has remained unchanged over the past 5 years with $80 \%$ and $70 \%$ of patients being alive, respectively [22]; frequent hospitalizations due to non-device and device related issues were noted [23]. The seventh INTERMACS reports have demonstrated a decrease in MCS as a bridge to HT (BT) strategy [24] and the opposite trend occurred for MCS use as a DT strategy with an increase from $28.6 \%$ (2008-2011) to $45.7 \%$ (2014).

The INTERMACS registry developed 7 clinical profiles to allow optimal selection of patients for MCS (mechanical circulatory support) (Table 1).

Table 1. INTERMACS Profiles Classification.

\begin{tabular}{ll}
\hline Profile & Description \\
\hline 1 & Critical cardiogenic shock \\
\hline 2 & Progressive decline on inotropic support \\
\hline 3 & Stable but inotrope - dependent \\
\hline 4 & Resting symptoms home on oral therapy \\
\hline 5 & Exertion - intolerant \\
\hline 7 & Exertion - limited \\
\hline NYHA, New York Heart Association \\
\hline
\end{tabular}

Many questions rise about MCS: first of all the timing of implantation. Treating patients with severe and compromise organ function is associated with poor outcomes, meanwhile initiating this therapy too early in the disease course may not be beneficial or cost effective.
The ROADMAP trial demonstrated that early LVAD implantation in lower INTERMACS profiles outcomes is equally favourable with improvements in health related quality of life (QoL) [26]: in this trial, to all the enrolled patients, was offered the implantation of a continuous flow LVAD and they compared patients who underwent implantation to those who choose medical therapy (11 of the 196 patients enrolled, 95 underwent implantation of an LVAD). By intention to treat, there was no difference in mortality, but those who had LVAD implantation demonstrated qualitative improvements in functional capacity, quality of life and depression.

Whether these benefits exceed those of optimal medical management remains a subject of debate and a prime issue for well-designed clinical trials. RV failure (RVF) ranges from $6 \%$ to $44 \%$, varying mostly due to differences in RVF definition, different types of LVADs and differences in patient populations included in studies [27-47]. Acute RVF, characterized by the Interagency Registry for Mechanically Assisted Circulatory Support (INTERMACS):

Causes systemic congestion, altered drug metabolism, malnutrition, diuretic resistance and poor quality of life [48]. May lead to impaired LVAD flow, difficulty in weaning from cardio-pulmonary bypass (CPB), decreased tissue perfusion and multi-organ failure [49].

Is associated with increased peri-operative mortality, prolonged length of stay and worse survival even after cardiac transplantation [28, 30, 48,50].

Identifying LVAD patients at risk for RVF postoperatively still remains an unsolved problem (Table 2) $[30,36]$.

Table 2. Interagency registry for Mechanically Assisted Circulatory Support Definition of Right Ventricular Failure.

\begin{tabular}{|c|c|}
\hline \multirow{9}{*}{ RVF definition } & Symptoms or findings of persistent RVF characterized by both of the following: \\
\hline & Elevated CVP documented by: \\
\hline & 1. Right atrial pressure $>16 \mathrm{mmHG}$ on right heart catheterization \\
\hline & 2. Significantly dilated vena cava with no inspiratory variation on echocardiography \\
\hline & 3. Elevated jugular venous pressure \\
\hline & Manifestations of elevated CVP characterized by: \\
\hline & 1. Peripheral edema $(\geq 2+)$ \\
\hline & 2. Ascites or hepatomegaly on exam or diagnostic imaging \\
\hline & 3. Laboratory evidence of worsening hepatic (total bilirubin $>2.0 \mathrm{mg} / \mathrm{dl}$ ) or renal dysfunction (creatinine $>2.0 \mathrm{mg} / \mathrm{dl}$ ) \\
\hline \multicolumn{2}{|r|}{ Severity Scale } \\
\hline \multirow{4}{*}{ Mild } & Patients meets both criteria for RVF plus: \\
\hline & Post-implant inotropes, inhaled oxide or intravenous vasodilators not continued beyond post-op day 7 after VAD implant \\
\hline & And \\
\hline & Post-implant inotropes, inhaled oxide or intravenous vasodilators not continued beyond post-op day 7 after VAD implant \\
\hline \multirow{5}{*}{ Moderate } & Patients meets both criteria for RVF plus: \\
\hline & $\begin{array}{l}\text { Post-implant inotropes, inhaled nitric oxide or intravenous vasodilators continued beyond post-op Day } 7 \text { and up to post-op } \\
\text { Day } 14 \text { after VAD implant }\end{array}$ \\
\hline & Patients meets both criteria for RVF plus: \\
\hline & CVP or right atrial pressure $>16 \mathrm{mmHG}$ \\
\hline & AND \\
\hline
\end{tabular}


Prolonged post-implant inotropes, inhaled nitric oxide or intravenous vasodilators continued beyond post-op Day 14 after VAD implant

\begin{tabular}{ll}
\hline & Patients meets both criteria for RVF plus: \\
& CVP or right atrial pressure $>16 \mathrm{mmHG}$ \\
Severe & AND \\
& Need for right ventricular assist device at any time after VAD implant \\
& OR \\
\hline Severe-acute & Death during VAD implants hospitalization with RVF as primary cause \\
\hline CVP, central venous; RVF, right ventricular failure; VAD, ventricular assist device
\end{tabular}

In medically nonresponsive patients, implantation of a right ventricular assist device (RVAD) might be necessary $[27,28,33,36,42,51,52]$.

It's of extreme importance to take into account that the incidence of the RVF increases with the decrease of patient's intermacs class [24].

\section{Influence of LVAD on RV Function}

Intrinsic RV dysfunction [53], ischemia [54], intraoperative events [29,55] and LVAD management strategies [56] have all been implicated in RVF. Biventricular dysfunction is a common end point for stage D heart failure where chronically elevated left-sided filling pressures have induced high pulmonary vascular resistance (PVR), resulting in secondary pulmonary hypertension and subsequently RVF. Acute unloading of the left ventricle, seen after successful LVAD implantation, drops the PCWP, thereby relieving congestion and cardiac output recovery [57].

As the LVAD decompresses the LV and reduces LV enddiastolic pressure, pulmonary artery pressure (PAP) should decrease. This will lead to a decreasing in RV afterload furthermore resulting in an improved RV function with an increased RV preload to match the LVAD. The time frame in which this occurs is variable and is possible only with a considerable change of PVR (pulmonary vascular resistance) and PCA (pulmonary arterial compliance), noting that pulmonary hypertension resolution is not universal, in addition, LV unloading from an LVAD typically reduces tricuspid regurgitation (TR) through a decreased RV after-load [58]. Volume resuscitation during the peri-operative period may also exacerbate RV dilation and TR [59]. Tachyarrhythmia's also contribute to RVF. Atrial arrhythmias occur in more than $20 \%$ of LVAD patients and double the risk of RVF [60]. In a recent study [61], PVR (pulmonary vascular resistance) and EA declined, however PCA (pulmonary arterial compliance) increased early post-LVAD implantation, confirming that LVAD implantation alone reduces both resistive and pulsatile components of RV load. Despite that, RAP (right atrial pressure) did not decline early post-LVAD. RAP: PAWP (pulmonary arterial wedge pressure or PAWP) increased and the relationship of $\mathrm{RV}$ load to $\mathrm{RV}$ adaptation (whether expressed by EA/RAP or EA/RAP: PAWP) get worst and remained stable over time.
Two considerations can clearly be inferred:

1. RV afterload declines early after LVAD and continues to decline with prolonged support;

2. RV adaptation to load worsens after implantation and this relationship remains constant over time.

In Addition, the effect of ventricular interdependence is most prominent in a setting of loading changes such as after LVAD. Of note, excessive left-ward shift of the IVS, particularly with overly aggressive LV decompression with continuous-flow (CF) LVADs, may also decrease septal contribution to RV contraction, leading to RVF (Figure 1) [57,62].

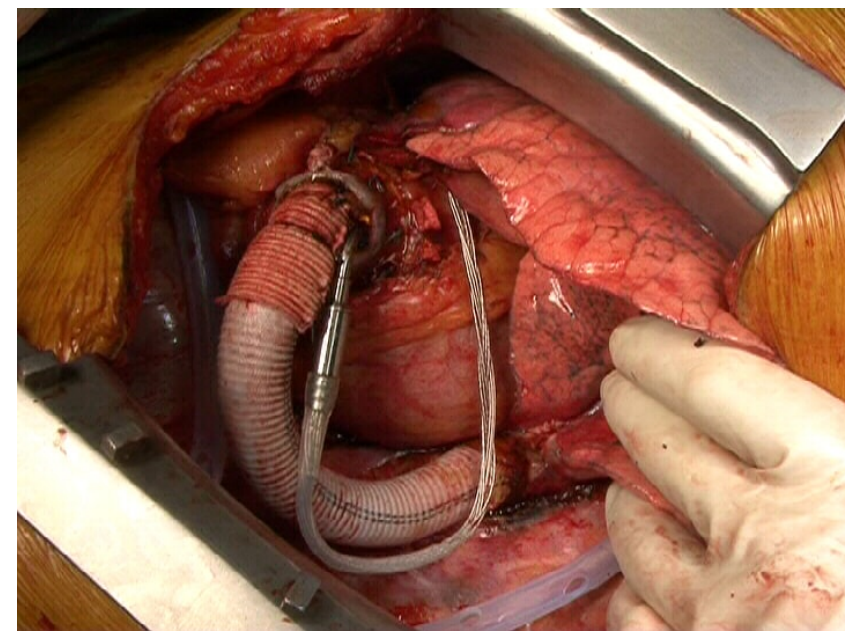

Figure 1. Implantation of JARVIK 2000, this is a thumb-sized titanium pump implanted inside the weakened, failing heart to boost its output of blood to the body.

\section{Predicting RVF and Patients Selection: Clinical Variables, Echocardiography, Hemodynamic Variables}

In the current era, right ventricular mechanical support is mainly available to those patients who are listed for cardiac transplantation, thereby placing profound importance in identifying those at risk for postoperative right ventricular failure. In addition, prognosis of patients treated with biventricular assist devices (BiVAD) is worse than prognosis of those treated with LVAD [20,63]. Analysis of international registry data has identified RV dysfunction requiring 
biventricular support as the most prominent risk factor for early mortality after VAD implantation [24].

Either way, the process of Identifying patients at high risk of RVF improves patient selection and allows for implementing strategies to avoid post-operative RVF: assessment of right ventricular function should incorporate a combination of imaging findings with hemodynamic and biochemical data.

Numerous pre-operative risk scores have been developed to quantify the risk of RVF in LVAD candidates. Female gender, nonischemic etiology, prior cardiac surgery, need for an intraaortic balloon pump, inotrope dependency, vasopressor use and need for mechanical ventilation are all recognized as risk factors for RVF. Biochemical parameters (including elevated serum creatinine, blood urea nitrogen (BUN), bilirubin, aspartate aminotransferase) suggest increased risk of RVF [28, 29, 33, 36,41, 64]. Special attention should be directed toward the arrhythmia burden, because significant ventricular arrhythmias may result in hemodynamic alterations: strong consideration should be given to biventricular MCS in patients with very frequent or refractory ventricular arrhythmia. The presence of peripheral arterial disease at the time of LVAD implantation may increase the risk of 1) stroke, 2) limb and mesenteric ischemia.

Of note, renal and hepatic dysfunction typically predict underlying chronicity of the disease and a worse right heart function [65].This predisposes to a greater propensity for bleeding and infection-related complications. However, on average, both renal and hepatic function improves by six months following LVAD implantation [66]. Poor nutritional status and frailty increase the risk of death following LVAD implantation $[15,67,68]$.

Considering echocardiography, we can find predictive of RVF: LA dimension [69, 70]; TAPSE [40,69]; Em/SLAT (pulsed Doppler trans-mitral E Wave/tissue Doppler lateral systolic velocity ratio) [71]; Basal RVEDD (RV end-diastolic diameter [71]; Pre-operative S'<4.4 cm/s, RV-E/E' >10 (45); Absolute RV longitudinal strain $<14 \%[30,45,72]$; Longitudinal strain of $\mathrm{RV}$ free wall [73]; RV end diastolic volume index [74]; RV ejection fraction [74]; RV end diastolic diameter [38]; TR regurgitation[38,74]; $\mathrm{R} / \mathrm{L}$ ratio $[75,76]$. Each of these variables was found to be significant or less significant, depending on the study (Table 3).

Table 3: 1) LVAD: left ventricular assist device; 2) RVF: right ventricular failure; 3) RVAD: right ventricular assist device; 4) LVEDD: left ventricular end-diastolic dimension; 5) RVSWI: right ventricular stroke work index; 6) BTT: bridge to transplant; 7) DT: destination therapy; 8) BTR: bridge to recovery ; 9) BTC: bridge to candidancy ; 10) TAPSE: tricuspid annular plane systolic excursion; 11) RIMP: index of myocardial performance; 12) CVP: central venous pressure ; 13) IABP: Intra-Aortic Balloon Pump; 14) ACE-I: angiotensin-converting-enzyme inhibitor; 15) ARB: angiotensin II receptor blocker 16) PCWP: Pulmonary capillary wedge pressure; 17) BUN: blood urea nitrogen; 18) R/L: righ ventricular to left ventricular diameter ratio; 19) BVAD: biventricular assist device; 20) TR: tricuspid regurgitation; 21) PAP: pulmonary artery pressure; 22) BSA: body surface area; 23) $S$ ': systolic velocity; 24) $R V-E / E$ ': the ratio of tricuspid peak velocity of early filling $(E)$ to early diastolic tricuspid annular velocity (E'); 25) Em/SLAT: pulsed Doppler transmitral E Wave and tissue Doppler lateral systolic velocity ratio; 26) RVEDD: RV enddiastolic diameter; 27) LA : left atrium

\begin{tabular}{|c|c|c|c|c|c|c|}
\hline First Author and Year & $\mathrm{N}^{\circ}$ & vad TYPE & AIM & rvf dEFINITION AND INCIDENCE & Events/Outcomes; Risk factors and Comment & SDF \\
\hline Potapov[38] 2008 & 54 & $\begin{array}{l}\text { Pulsatile } \\
43 \%\end{array}$ & flow & $\begin{array}{l}\text { In the first } 48 \mathrm{~h} \\
\text { Two of: } \\
\text { - mean arterial } \\
\text { pressure } \leq 55 \mathrm{~mm} \mathrm{Hg} \text {; } \\
\text { - central venous pressure } \geq 16 \mathrm{~mm} \\
\mathrm{Hg} \text {; } \\
\text { - mixed venous saturation } \leq 55 \% \text {; } \\
\text { - cardiac index } \\
<2 \text { liters/min/m2; and inotropic support } \\
>20 \text { units. } \\
\text { Need } \\
\text { for an RVAD(3) after LVAD insertion was } \\
\text { regarded as a } \\
\text { single criterion identifying RV failure. } \\
\text { RVF } 17 \%\end{array}$ & $\begin{array}{l}\text { No differences were found regarding type of } \\
\text { LVAD(1) } \\
\text { Pre-operative left ventricular end-diastolic } \\
\text { dimension (LVEDD) significant for RVF( } 2 \text { ) } \\
\text { Pre-operative tricuspid regurgitation was } \\
\text { significantly more pronounced in patients with } \\
\text { RVF ( } p=0.03) \text {; } \\
\text { Tricuspid regurgitation was graded as follows: } \\
\text { Gradel, regurgitation jet reaches middle part of } \\
\text { the right atrium; Grade II, regurgitation jet } \\
\text { reaches roof of the right atrium; Grade III, } \\
\text { regurgitation jet into caval veins; and Grade IV, } \\
\text { pulsation of the hepatic and jugular veins. } \\
\text { RVSWI }(4) \text { not significant } \\
\text { No stratification for Intermacs class, usage of } \\
\text { old generation of LVAD }\end{array}$ & \\
\hline
\end{tabular}

\begin{tabular}{|c|c|c|c|c|c|}
\hline $\begin{array}{l}\text { PUWANANT[40] } \\
2008\end{array}$ & 33 & $\begin{array}{l}\text { Pulsatile flow } \\
55 \% \\
\text { Continuous flow } \\
45 \%\end{array}$ & $\begin{array}{l}\text { BTT(5) } \\
67 \% \\
\text { DT(6) } \\
21 \% \\
\text { BTR(7) } \\
12 \%\end{array}$ & $\begin{array}{l}\text { The requirement of inotropic agents or } \\
\text { pulmonary vasodilators for more than } 14 \\
\text { days post-operatively } \\
\text { RVF } 33 \%\end{array}$ & $\begin{array}{l}\text { Intermacs class not reported; Etiology reported } \\
\text { Different Devices used. } \\
\text { Patients with RV failure had significantly higher } \\
\text { pulmonary systolic pressures, whereas RVSWI, } \\
\text { mean pressures, and pulmonary vascular } \\
\text { resistance were not significantly different } \\
\text { between those with and without RV failure. } \\
\text { TAPSE(8) significant } \\
\text { There were no significant differences in RV } \\
\text { fractional area change, right atrial volume, right } \\
\text { atrial volume index, hepatic vein systolic and } \\
\text { diastolic Doppler velocities, RIMP(9), RVSWI } \\
\text { and severity of tricuspid regurgitation. }\end{array}$ \\
\hline
\end{tabular}




\begin{tabular}{|c|c|c|c|c|c|}
\hline $\begin{array}{l}\text { ALBA[77] } \\
2009\end{array}$ & 54 & $\begin{array}{l}\text { Pulsatile flow } \\
\text { Continuous flow }\end{array}$ & $\begin{array}{l}\text { BTR, } \\
\text { BTC }(10) \\
\text { BTT }\end{array}$ & $\begin{array}{l}\text { Clinical parameters of low LVAD output, } \\
\text { and high central venous pressure } \\
(>15 \mathrm{~mm} \mathrm{Hg} \text { ), and the use of inhaled } \\
\text { nitric oxide }>48 \mathrm{~h} \text {, inotropic support }>14 \\
\text { days, or need for RVAD after LVAD } \\
\text { implantation) } \\
\text { RVF } 54 \% \text { in Intermacs } 1-2 \\
\text { RVF } 58 \% \text { in Intermacs } 3-4\end{array}$ & $\begin{array}{l}\text { Intermacs reported. Different type of LVAD } \\
\text { used. } \\
\text { LVAD only for Intermacs } 1-4 \text {. } \\
\text { Intermacs not predictive for RVF. } \\
\text { The overall survival was significantly lower in } \\
\text { Intermacs } 1 \text { and } 2 \text { vs } 3 \text { and } 4 \text {. }\end{array}$ \\
\hline $\begin{array}{l}\text { DRAKOS[41] } \\
2010\end{array}$ & 175 & $\begin{array}{l}\text { Continuous } \\
14 \% \\
\text { Pulsatile } \\
86 \%\end{array}$ & $\begin{array}{l}\text { BTT } 58 \% \\
\text { DT } 42 \%\end{array}$ & $\begin{array}{l}\text { RVAD implantation } \\
\text { Inotropes }>14 \text { days } \\
\text { IV inotropes }>14 \text { days } \\
\text { RVF } 44 \%\end{array}$ & $\begin{array}{l}\text { The survival rate between the non-RVF and } \\
\text { RVF } \\
\text { groups was } 96 \% \text { versus } 80 \% \text { at } 30 \text { days } \\
\text { ( } p=0.0012), 90 \% \text { versus } 70 \% \text { at } 180 \text { days ( } p= \\
0.0011) \text {, and } 83 \% \text { versus } 62 \% \text { at } 365 \text { days ( } p= \\
0.002 \text { ). } \\
\text { Destination therapy (OR } 3.3 \text { ) } \\
\text { Continuous } 14 \% \text { IABP (OR } 3.9 \text { ) } \\
\text { Peripheral vascular resistance (OR } 2-4.1 \text { ) } \\
\text { Inotrope dependency (OR } 2.5) \\
\text { Obesity (BMI } \geq 30 \mathrm{~kg} / \mathrm{m} 2)(\mathrm{OR} 2.0) \\
\text { ACE or ARB (OR 0.5) } \\
\beta \text {-Blocker (OR } 1.6 \text { ) } \\
\text { RVSWI: } p \text { Value =0.08; } \\
\text { No stratification for Intermacs class, usage of } \\
\text { old generation } f \text { LVAD. }\end{array}$ \\
\hline
\end{tabular}

\begin{tabular}{|c|c|c|c|c|}
\hline $\begin{array}{l}\text { KORMOS[29] } \\
2010\end{array}$ & 484 & $\begin{array}{l}\text { Continuous } \\
\text { Flow } 100 \%\end{array}$ & $\begin{array}{l}\text { BTT } \\
100 \%\end{array}$ & $\begin{array}{l}\text { Group 1: RVAD implantation } \\
\text { Group 2: inotropes for at least } 14 \text { days } \\
\text { Group 3: late inotropic support starting } \\
>14 \text { days after implantation } \\
\text { RVF } 20 \%(\text { early RVF }=13 \%)\end{array}$ \\
\hline
\end{tabular}

Multivariate analysis revealed that a CVP/ PCWP ratio of greater than 0.63 (OR, 2.3; 95\% $\mathrm{Cl}, 1.2-4.3$; $\mathrm{P}<.009)$, need for ventilatory support (OR, 5.5; 95\% Cl, 2.3-13.2; $\mathrm{P}<.001$ ), and a preoperative BUN value of greater than $39 \mathrm{mg} / \mathrm{dL}(\mathrm{OR}, 2.1 ; 95 \% \mathrm{Cl}, 1.1-4.1 ; \mathrm{P}<.02)$ were the significant independent preoperative predictors of early RVF after LVAD implantation In univariate analysis RVSWI predictive of RVF $(p=0.04)$

\begin{tabular}{|c|c|c|c|}
\hline $\begin{array}{l}\text { KUKUCKA[75] } \\
2011\end{array}$ & 115 & $\begin{array}{l}\text { Mainly } \\
\text { Continuous } \\
\text { Flow }\end{array}$ & $\begin{array}{l}2 \text { of the following criteria in the absence } \\
\text { of cardiac tamponade within the first } 48 \mathrm{~h} \\
\text { after surgery: } \\
\text { - mean arterial pressure }<55 \mathrm{~mm} \mathrm{Hg} \text {, } \\
\text { - central venous pressure }>16 \mathrm{~mm} \mathrm{Hg} \\
\text { - mixed venous saturation }<55 \% \text {, } \\
\text { - cardiac index }<2 \mathrm{~L} / \mathrm{min} / \mathrm{m} 2 \text {, inotropic } \\
\text { support }>20 \text { units. } \\
\text { RVF } 3,9 \%-31,6 \%\end{array}$ \\
\hline
\end{tabular}

Intermacs 1 and 2 excluded and considered for primary BiVAD implantation.

Were scheduled for BiVAD implantation:

Severe disturbed RV geometry or function in trans-thoracic echocardiography, Tricuspid incompetence grade III or IV

$\mathrm{R} / \mathrm{L}$ ratio seemed the most promising parameter for Identifying the risk for RVF.

RVF developed in 3 of 77 patients (3.9\%) who had an $R / L$ ratio $\leq 0.72$. Of the 38 patients with a $R / L$ ratio $\geq 0.72$, RVF developed in 12 $(31.6 \%)$, resulting in a sensitivity of 0.8 at a specificity of 0.74 .

\begin{tabular}{lclll}
\hline GRANT [30] & 117 & $\begin{array}{l}\text { Continuous } \\
\text { Flow } 100 \%\end{array}$ & $\begin{array}{l}\text { BTT } \\
67\end{array}$ & $\begin{array}{l}\text { RV failure was defined as unplanned } \\
\text { insertion of an RVAD or the use of an } \\
\text { intravenous inotrope for }>14 \text { days post- } \\
\text { operatively } \\
\text { RVF } 40 \%\end{array}$
\end{tabular}

No clinical predictors of RV failure included preoperative inotrope use, bilirubin, cardiac index and pulmonary vascular resistance. When combined with the Michigan RV risk score in a multivariate model, RV peak longitudinal strain was a significant contributor to the model. RV peak longitudinal strain of <$9.6 \%$ was assigned a weighting of 2.5 points based on the relative odds ratios for RV failure of creatinine and bilirubin in our cohort. RV-to-LV diameter ratio not significant; TAPSE not significant. RVSWI and CVP(11) not significant(maybe because these values were used to guide the strategy for planned biventricular support)

No stratification for Intermacs class.

\section{RAINA[70]}

2013
55

Continuous flow DT $100 \%$ $93 \%$
Need for inotropes for $\geq 14$ days after Invasive pulmonary artery pressures and LVAD implantation or need for temporary cardiac index were similar between groups. RV RVAD placement after LVAD implantation. RVF $29 \%$
LVAD stroke work index was lower in the RVF group compared with the no RVF group $(367 \pm 221$ vs $603 \pm 286 \mathrm{~mm} \mathrm{Hg} \mathrm{x} \mathrm{mL/m2;} \mathrm{P} \mathrm{=} \mathrm{.003)}$

Ratio of RV to LV end-diastolic diameter was not different between the 2 groups. In a multivariate model left atrial volume and Intermacs class were predictive 


\begin{tabular}{|c|c|}
\hline DANDEL [74] & 475 \\
\hline
\end{tabular}

Unplanned insertion of a RVAD Prolonged reduction of PVR by nitric oxide or iloprost inhalation ( \pm oral sildenafil) and ir
intravenous inotrope therapy for $>10$ thos intravenous inotrope therapy for cardiac index $(\mathrm{Cl})>2 \mathrm{~L} / \mathrm{min} / \mathrm{m} 2$
Patients with atrial fibrillation and on hemodialysis were excluded. Implant of a BiVAD or a total artificial heart in patients with reversible $T R(12)$ grade $>3$ and usually also in those with TR grade $<3$ if RV dilation and alteration of RV geometry

Ischemic cardiomyopathy reported. In $>90 \%$ $\mathrm{RV}$ failure during the first day. In patients free of RVF: $41.3 \%$ improvement of RV; $45 \%$ no changes; 13.7 worsening without RVF.

In multivariable analysis of predictors of RVF only CVP and PAP reached statistical significance. In univariate analysis PAP $>50$ mmHG high predictive value for freedom from $\mathrm{RV}$ failure.

$\mathrm{PAP}<50 \mathrm{mmHG}$ and tricuspidal regurgitation $>2$ : high predictive value for $\mathrm{RV}$ failure

$\begin{array}{lllll}\text { VIVO [76] } & 109 \begin{array}{ll}\text { Continuous } \\ 2013\end{array} & \text { BTT49\% } & \text { Requirement of a RVAD or } \geq 14 \\ & \text { Flow 100\% } & \text { BC 2\% } & \text { consecutive days of inotropic support. } \\ \text { DT } 51 \% & \text { RVF 22,9\% }\end{array}$

Stratification for Intermacs class and etiology. There were no significant differences between groups in BSA, etiology of cardiomyopathy, comorbid diseases, device strategy or INTERMACS profile.

None of the invasive hemodynamic measurements by right heart catheterization, including RV stroke work index, was strongly associated with RVF.

In the multivariate analysis, patients with an increased RV/LV diameter continued to have a higher risk for RVF

$\begin{array}{ll}\text { KATO [45] } 68 & \text { 1)The need for salvage right ventricular } \\ 2013 & \text { assist device (RVAD); } \\ & \text { Or 2) persistent need a } \\ & \text { for inotrope and/or pulmonary } \\ & \text { vasodilator therapy 14 days after } \\ & \text { surgery } \\ & \text { RVF } 35,3 \%\end{array}$

$89,7 \%$ male

Multivariable analysis not performed No stratification for Intermacs class.

RVSWI not significant. Univariate analysis fo RV echo parameters revealed that lower TAPSE, lower S', higher RV-E/E', and lower absolute value of RV global strain obtained before surgery were associated with RVF at day 14

Pre-operative $\mathrm{S}^{\prime}<4.4 \mathrm{~cm} / \mathrm{s}, \mathrm{RV}-\mathrm{E} / \mathrm{E}^{\prime}>10$ and absolute RV longitudinal strain $<14 \%$ were used for RVF prediction model.

ROC curve analysis revealed that if patients met criteria for two preoperative echo risk parameters, RVF post-LVAD could be predicted with a sensitivity of $87.5 \%$, specificity of $70.4 \%$, and a predictive accuracy of $76.5 \%$

AISSAOUI [71] $\quad 42 \begin{aligned} & \text { Continuous } \\ & 2015\end{aligned} \quad$ Flow $100 \%$

Definition adopted by Intermacs RVF $23 \%$
Need for placement of a temporary right Intermacs class reported; Etiology reported ventricular assist device or the use of Strain rate (SR), longitudinal strain and TAPSE inotropic agents for 14 days not significant

$\operatorname{RVF}(57,1 \%)$

Multivariable analysis identified as predictors for RVF:

- INTERMACS level 1

- Em/SLAT

- Basal RVEDD

Independent predictors of severe RVF requiring RVAD

support after cf-LVAD implantation were lesser TAPSE

(P 1/4 .013; odds ratio, 0.613; 95\% confidence interval

[Cl], 0.417-0.901) and smaller LA (P 1/4 .007 odds ratio,

0.818; $95 \% \quad \mathrm{Cl}, \quad 0.707-0.947)$. Receiver operating

characteristics curve for TAPSE showed an area under the

curve of $0.85(95 \% \mathrm{Cl}, 0.781-0.923)$, with cutoff TAPSE

less than $12.5 \mathrm{~mm}$ having $84 \%$ sensitivity and

$75 \%$

specificity

Etiology: almost entirely Dilated

Cardiomyopathy Independent predictors of 
severe RVF requiring RVAD: TAPSE $(P=0.013$; odds ratio, $0.613 ; 95 \%$

[Cl], 0.417-0.901)

Smaller LA ( $P=0,007$; odds ratio $0.818 ; 95 \%$ $\mathrm{CI}$ 0.707-0.947). Receiver Characteristics curve for TAPSE showed an area under the curve of $0.85(95 \% \mathrm{Cl}, 0.781-0.923)$, with cutoff TAPSE less than $12.5 \mathrm{~mm}$ having $84 \%$ sensitivity and $75 \%$ specificity

Intermacs class reported was comparable across both Groups $(\mathrm{P}=0.787)$

RVSWI: not significant ( $p$ value 0,911 )

Overall cumulative survival on LVAD support didn't statistically differ between the RVAD and the control group

$\begin{array}{lclll}\text { KALOGEROPOULOS[72] } & 41 & \begin{array}{l}\text { Continuous } \\ \text { Flow } 100 \%\end{array} & \text { BT } 41,5 \% & \text { Definition adopted by Intermacs } \\ 2016 & & \text { DT } 58,5 \% & \text { RVF } 23 \%\end{array}$

Intermacs 1 not included; Ischemic etiology (34\%). Conventional RV function parameters were not predictors. RV global longitudinal strain was the most important predictor of RVF

Elevated CVP has been identified as one of the significant predictors of RVF after LVAD and it is still used in clinical decision making. Invasive hemodynamic are essential in determining patients at greater risk for post-operative RVF. Multiple hemodynamic abnormalities are associated with RVF. No single factor is consistent across studies, but elevated CVP or $\mathrm{CVP} /$ pulmonary capillary wedge pressure (PCWP) ratio most commonly correlate with RVF [29,64]. Particularly concerning for RVF is elevated CVP in the setting of low PAPs $[28,74]$. In a study low cardiac index and low RV stroke work index (RVSWI) [42] were identified as risk factors.Of note, RVSWI is not a risk factor in several studies. So, surrogates of reduced RV contractility, i.e. low pulmonary artery systolic pressure and RV stroke work index, can be considered markers of risk but have not yielded substantial predictive information $[29,30,41,64]$. Reverse remodelling of pulmonary vasculature can potentially occur by continuing unloading, and, unlike for heart transplantation, elevated pulmonary vascular resistance does not predict post implant RVF [29,36,78].

To notice the fact that these studies tried to built up some scores to help clinical practice in the decision on: 1) which type of device to implant; 2) which type of patients; 3)proper implantation time. Notably, most scores are derived from patient populations supported with earlier-generation pulsatileflow pumps and hence are not fully representative of the present-day LVAD population.

\section{Results Postoperative}

Different authors state:

The need for an RVAD is associated with worse outcomes [34], but elective RVAD correlates with better long-term survival than an emergency implantation [35].Risk assessment for RHF should be performed preoperatively to assess the need for initial BiVAD implantation or total artificial heart;Elective BiVAD implantation has better outcomes than unplanned urgent institution of mechanical RV support [29,30,52].The ability to wean from RVAD support varies widely in clinical trials, from $20 \%$ to $70 \%$. (Figure 2) [31,79-81].

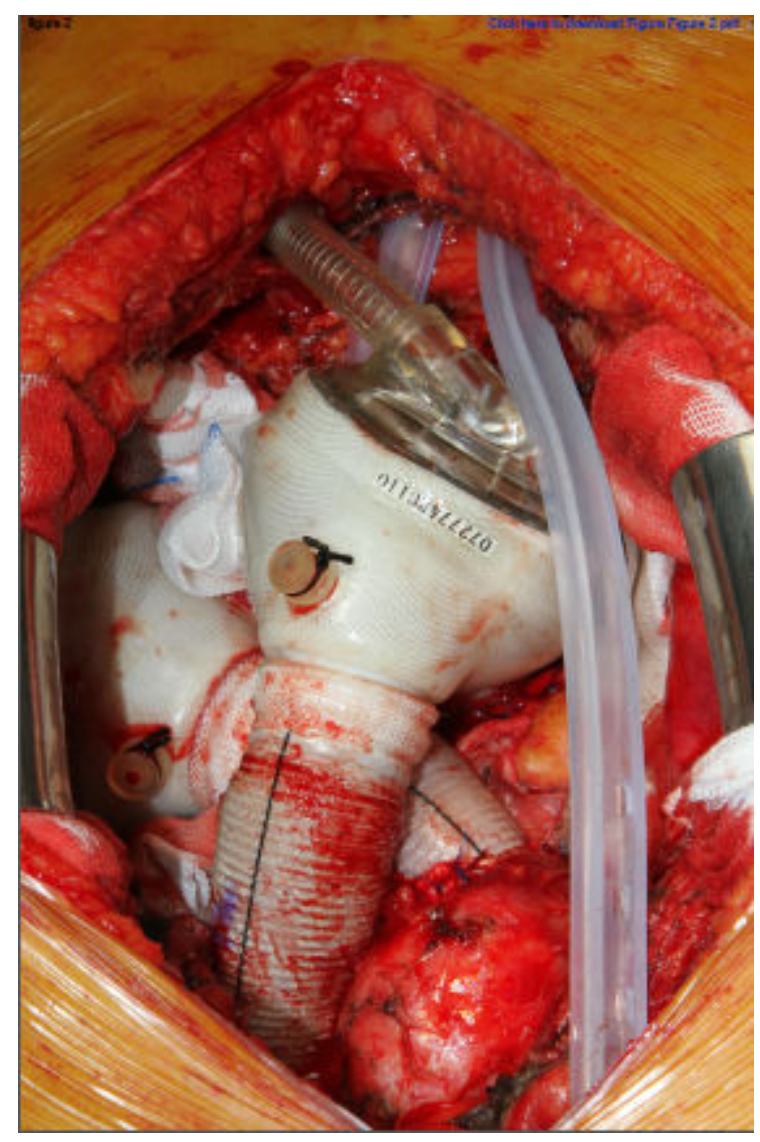

Figure 2. The SynCardia temporary Total Artificial Heart, it replaces both heart ventricles. Is approved by FDA (food and drug administration) for use as a bridge to transplant, as well as destination therapy.

\section{The current evidence: there is not a strong current evidence.}

Multiple risk scores using clinical, echocardiographic, and hemodynamic factors exist to predict RVF. However, no single variable adequately discriminates or is reliable for patient selection. Considering the great heterogeneity of the literature in terms of: 
1. The lack of stratification, in almost all of the work, for Intermacs classes;

2. The lack of stratification, in some work, for the etiology of heart failure;

3. The presence of devices belonging to different generations;

4. The inhomogeneity of the definition of RVF, combined with the inhomogeneity of the severity of the clinical condition of the patients enrolled;

5. The presence of large standard deviations considering the cut-off values of RVSWI used to predict the RVF next to the implantation;

6. The lack of data, resulting from careful and precise selection criteria, which can guide the choice where it is convenient to schedule the Bi-VAD implantation rather than a use the support of the right ventricle only in terms of rescue therapy;

7. The presence of surveys with determined arbitrarily cut-off value of clinical conditions or echocardiography, that directly addressed the patients to Bi-VAD rather than being randomized;

\section{Conclusions}

It's time to develop a well-crafted informed consent process for patients and their caregivers to help them understand the expectations post implantation

It is hoped that improvements will improve the beneficial effects of LVAD therapy. We are far from a completely and clear knowledge about the prognosis of our patients. Waiting a randomized multicentre study, we just have to rely on clinical judgment of multidisciplinary experts, who can use their expertise in the field, and on the few data in the literature, derived from studies in which it was used only the new generation of devices.

References

1. Roger VL. Epidemiology of heart failure. Circ Res. 2013;113:646-59.

2. Go AS, Mozaffarian D, Roger VL, et al. Heart disease and stroke statistics-2013 update: a report from the American Heart Association. Circulation. 2013;127:e6-e245.

3. Rose EA, GelijnsAC, Moskowitz AJ, et al. Long-term use of a left ventricular assist device for end-stage heart failure.N Engl JMed. 2001;345:1435-43.

4. Miller LW, Pagani FD, Russell SD, et al. Use of a continuous-flow device in patients awaiting heart transplantation. N Engl J Med. 2007;357:885-96.

5. Lietz K, Long JW, Kfoury AG, et al. Outcomes of left ventricular assist device implantation as destination therapy in the post-REMATCH era: implications for patient selection. Circulation. 2007;116:497-505.

6. Lund LH, Matthews J, Aaronson K. Patient selection for left ventricular assist devices. Eur J Heart Fail. 2010;12:434-43.

7. Atluri P, Fairman AS, Macarthur JW, et al. Continuous flow left ventricular assist device implant significantly improves pulmonary hypertension, right ventricular contractility, and tricuspid valve competence. J Card Surg. 2013; 28:770-5.

8. Pauwaa S, Bhat G, Tatooles AJ, et al. How effective are continuous flow left ventricular assist devices in lowering high pulmonary artery pressures in heart transplant candidates? Cardiol J. 2012;19:153-8.

9. Slaughter MS, Meyer AL, Birks EJ. Destination therapy with left ventricular assist devices: patient selection and outcomes. Curr Opin Cardiol. 2011;26:232-6.

10. Cowger J, Sundareswaran K, Rogers JG, et al. Predicting survival in patients receiving continuous flow left ventricular assist devices: the HeartMate II risk score. J Am Coll Cardiol. 2013;61:313-21.

11. Lietz K. Destination therapy: patient selection and current outcomes. J Card Surg. 2010;25:462-71.

12. Liden $\mathrm{H}$, Karason $\mathrm{K}$, Bergh $\mathrm{CH}$, et al. The feasibility of left ventricular mechanical support as a bridge to cardiac recovery. Eur J Heart Fail. 2007;9:525-30.

13. Long EF, Swain GW, Mangi AA. Comparative survival and cost-effectiveness of advanced therapies for end-stage heart failure. Circ Heart Fail. 2014;7:470-8.

14. Rose EA, Gelijns AC, Moskowitz AJ, et al. Long-term use of a left ventricular assist device for end-stage heart failure. N Engl J Med. 2001;345:1435-43.

15. Miller LW, Pagani FD, Russell SD, et al. Use of a continuous flow device in patients awaiting heart transplantation. N Engl J Med. 2007;357:885-96.

16. Slaughter MS, Rogers JG, Milano CA, et al. Advanced heart failure treated with continuous-flow left ventricular assist device. N Engl J Med. 2009;361:2241-51.

17. Rogers JG, Aaronson KD, Boyle AJ, et al. Continuous flow left ventricular assist device improves functional capacity and quality of life of advanced heart failure patients. J Am Coll Cardiol. 2010;55:1826-34.

18. Atluri P, Goldstone AB, Kobrin DM, et al. Ventricular assist device implant in the elderly is associated with increased, but respectable risk. Ann Thorac Surg. 2013; 96:141.

19. Kaczorowski DJ, Woo YJ. Who needs an RVAD in addition to an LVAD. Cardiol Clin. 2011;29:599-605.

20. Kirklin JK, Naftel DC, Pagani FD, et al. Sixh INTERMACS annual report: a 10,000-patient database. J Heart Lung Transplant. 2014;33:555-64.

21. Kirklin JK, Naftel DC, Pagani FD, et al. Sixh INTERMACS annual report: a 10,000-patient database. J Heart Lung Transplant. 2014;33:555-64.

22. Kirklin JK, Naftel DC, Kormos RL, et al. Third INTERMACS Annual Report: the evolution of destination therapy in the United States. J Heart Lung Transplant. 2011;30:115-23.

23. Potapov E, Meyer D, Swaminathan M, et al. Inhaled nitric oxide after left ventricular assist device implantation: a prospective, randomized, doubleblind, multicenter, placebo-controlled trial. J Heart Lung Transplant. 2011;30:870-8. 
24. Takeda K, Takayama H, Kalesan B, et al. Long-term outcome of patients on continuous-flow left ventricular assist device support. J Thorac Cardiovasc Surg. 2014;148:1606-14.

25. Kirklin JK, Naftel DC, Pagani FD, et al. Seventh INTERMACS annual report: 15,000 patients and counting. J Heart Lung Transplant. 2015;34:1495-1504.

26. Stevenson LW, Pagani FD, Young JB, et al. Intermacs profiles of advanced heart failure: The current picture. J Heart Lung Transplant. 2009; 28:535-41.

27. Estep JD, Starling RC, Horstmanshof DA, et al. Riskassessment and comparative effectiveness of left ventricular assist device and medical management in ambulatory heart failure patients: Results from the roadmap study. J Am Coll Cardiol. 2015;66:1747-61.

28. Kavarana MN, Pessin-Minsley MS, Urtecho J, et al. Right ventricular dysfunction and organ failure in left ventricular assist device recipients: a continuing problem. Ann Thorac Surg. 2002;73:745-50.

29. Dang NC, Topkara VK, Mercando M, et al. Right heart failure after left ventricular assist device implantation in patients with chronic congestive heart failure. J Heart Lung Transplant. 2006;25:1-6.

30. Kormos RL, Teuteberg JJ, Pagani FD, et al. Right ventricular failure in patients with the HeartMate II continuous-flow left ventricular assist device: incidence, risk factors, and effect on outcomes. J Thorac Cardiovasc Surg. 2010;139:1316-24.

31. Grant AD, Smedira NG, Starling RC, Marwick TH. Independent and incremental role of quantitative right ventricular evaluation for the prediction of right ventricular failure after left ventricular assist device implantation. J Am Coll Cardiol. 2012;60:521-8.

32. Takeda K, Naka Y, Yang JA, Uriel N, Colombo PC, Jorde UP. Outcome of unplanned right ventricular assist device support for severe right heart failure after implantable left ventricular assist device insertion. J Heart Lung Transplant. 2014;33:141-8.

33. Fukamachi K, McCarthy PM, Smedira NG, Vargo RL, Starling RC, Young JB. Preoperative risk factors for right ventricular failure after implantable left ventricular assist device insertion. Ann Thorac Surg. 1999; 68:2181-4.

34. Ochiai Y, McCarthy PM, Smedira NG, et al. Predictors of severe right ventricular failure after implantable left ventricular assist device insertion: analysis of 245 patients. Circulation. 2002;106:I198-202.

35. Schenk S, McCarthy PM, Blackstone EH, et al. Duration of inotropic support after left ventricular assist device implantation: risk factors and impact on outcome. J Thorac Cardiovasc Surg. 2006;131:447-54.

36. Scalia GM, McCarthy PM, Savage RM, Smedira NG, Thomas JD. Clinical utility of echocardiography in the management of implantable ventricular assist devices. J Am Soc Echocardiogr. 2000;13:754-63.

37. Matthews JC, Koelling TM, Pagani FD, Aaronson KD. The right ventricular failure risk score a pre-operative tool for assessing the riskof right ventricular failure in left ventricular assist device candidates. J Am Coll Cardiol. 2008;51:2163-72.

38. Slaughter MS, Pagani FD, Rogers JG, et al. Clinical management of continuous-flow left ventricular assist devices in advanced heart failure. J Heart Lung Transplant. 2010;29 Suppl:S1-39.

39. Potapov EV, Stepanenko A, Dandel M, et al. Tricuspid incompetence and geometry of the right ventricle as predictors of right ventricular function after implantation of a left ventricular assist device. J Heart Lung Transplant. 2008;27:1275-81

40. Lee S, Kamdar F, Madlon-Kay R, et al. Effects of the HeartMate II continuous-flow left ventricular assist device on right ventricular function. J Heart Lung Transplant. 2010;29:209-15.

41. Puwanant S, Hamilton KK, Klodell CT, et al. Tricuspid annular motion as a predictor of severe right ventricular failure after left ventricular assist device implantation. J Heart Lung Transplant. 2008;27:1102-7.

42. Drakos SG, Janicki L, Horne BD, et al. Risk factors predictive of right ventricular failure after left ventricular assist device implantation. Am J Cardiol. 2010;105:1030-5.

43. Fitzpatrick JR III, Frederick JR, Hsu VM, et al. Risk score derived from pre-operative data analysis predicts the need for biventricular mechanical circulatory support. J Heart Lung Transplant. 2008;27:1286-92.

44. Hennig F, Stepanenko AV, Lehmkuhl HB, et al. Neurohumoral and inflammatory markers for prediction of right ventricular failure after implantation of a left ventricular assist device. Gen Thorac Cardiovasc Surg. 2011;59:19- 24.

45. Topilsky Y, Oh JK, Shah DK, et al. Echocardiographic predictors of adverse outcomes after continuous left ventricular assist device implantation. JACC Cardiovasc Imaging. 2011;4:211-22.

46. Kato TS, Farr M, Schulze PC, et al. Usefulness of twodimensional echocardiographic parameters of the left side of the heart to predict right ventricular failure after left ventricular assist device implantation. Am J Cardiol. 2012;109:246-51.

47. Scherer M, Sirat AS, Moritz A, Martens S. Extracorporeal membrane oxygenation as perioperative right ventricular support in patients with biventricular failure undergoing left ventricular assist device implantation. Eur J Cardiothorac Surg. 2011;39:939-44.

48. Pettinari M, Jacobs S, Rega F, Verbelen T, Droogne W, Meyns B. Are right ventricular risk scores useful? Eur J Cardiothorac Surg. 2012;42:621-6.

49. Interagency Registry for Mechanically Assisted Circulatory Support (INTERMACS). AppendixA:Adverse event definitions: adult and pediatric patients (2013).

50. Kukucka M, Potapov E, Stepanenko A, et al. Acute impact of left ventriculaunloading by left ventricular assist device on the right ventricle geometry and function: effect of nitric 
oxide inhalation. J Thorac Cardiovasc Surg. 2011;141:1009-14.

51. Baumwol J, MacdonaldPS, Keogh AM, et al. Right heart failureand "failure to thrive" after left ventricular assist device: clinical predictors and outcomes. J Heart Lung Transplant 2011;30:888-95.

52. Furukawa K, Motomura T, Nosé Y. Right ventricular failure after left ventricular assist device implantation: the need for an implantable right ventricular assist device. Artif Organs 2005;29:369 -77.

53. Morgan J, John R, Lee B, Oz M, Naka Y. Is severe right ventricular failure in left ventricular assist device recipients a risk factor for unsuccessful bridging to transplant and post-transplant mortality. Ann Thorac Surg. 2004;77:859-63.

54. Fukuda S, Takano H, Taenaka Y, et al. Chronic effect of left ventricular assist pumping on right ventricular function. ASAIO Trans. 1988;34:712-5.

55. Daly RC, Chandrasekaran K, Cavarocchi NC, Tajik AJ, Schaff HV. Ischemia of the interventricular septum. A mechanism of right ventricular failure during mechanical left ventricular assist. J Thorac Cardiovasc Surg . 1992;103:1186-91.

56. Marzec LN, Ambardekar AV. Preoperative evaluation and perioperative management of right ventricular failure after left ventricular assist device implantation. Semin Cardiothorac Vasc Anesth. 2013;17:249-61.

57. Craig ML. Management of right ventricular failure in the era of ventricular assist device therapy. Curr Heart Fail Rep. 2011;8:65-71.

58. Moon MR,BolgerAF,DeAndaA, al.Septalfunctionduringleft ventricularunloading.Circulation.1997; 95:1320-7.

59. Morgan JA,PaoneG,NemehHW, et al. Impact of continuous-flow left ventricular assist devices upport on right ventricular function. J Heart Lung Transplant . 2013;32:398-403.

60. Krishan K, NairA, PinneyS, et al. Liberal use of tricuspidvalve annuloplasty during left-ventricular assist device implantation. Eur J Cardiothorac Surg .2012;41:213-7

61. Brisco M, Sundareswaran K, Milano CA, et al. The incidence, risk, and consequences of atrial arrhythmias in patients with continuous-flow left ventricular assist devices. J Card Surg. 2014;29:572-80.

62. Houston BA, Kalathiva RJ, Hsu S, et al. Right ventricular afterload sensitivity dramatically increases after left ventricular assist device implantation: A multi-center hemodynamic analysis. J Heart Lung Transplant. 2016;35:868-76.

63. Farrar DJ. Ventricular interactions during mechanical circulatory support. Semin Thorac Cardiovasc Surg. 1994;6:163-168.

64. Feldman D, Pamboukian SV, Teuteberg JJ, et al. The 2013 International Society for Heart and Lung Transplantation Guidelines for mechanical circulatory support:executive summary. J Heart Lung Transplant .2013;32:157-87.
65. Atluri P, Goldstone AB, Fairman AS, et al. Predicting right ventricular failure in the modern, continuous flow left ventricular assist device era. Ann Thorac Surg. 2013;96:857-63.

66. Matthews JC, Pagani FD, Haft JW, Koelling TM, Naftel DC, Aaronson KD. Model for end-stage liver disease score predicts left ventricular assist device operative transfusion requirements, morbidity and mortality. Circulation. 2010;121:214-20

67. Russell SD, Rogers JG, Milano CA, et al. Renal and hepatic function improve in advanced heart failure patients during continuous-flow support with the HeartMate II left ventricular assist device. Circulation. 2009;120:2352-57.

68. Dunlay SM, Park SJ, Joyce LD, et al. Frailty and outcomes after implantation of left ventricular assist device as destination therapy. J Heart Lung Transplant. 2014;33:359-65.

69. Dobbles F, Mauthner O, Milisen K. Frailty in left ventricular assist device destination therapy: putting a new motor in a rickety old car running out of gas? J Heart Lung Transplant. 2014;33:347-49.

70. Patil NP, Mohite PN, Sabashnikov A, et al. Preoperative predictors and outcomes of right ventricular assist deviceimplantation after continuous-flow left ventricular assist device implantation. J Thorac Cardiovasc Surg. 2015;150:1651-8.

71. Raina A, Seetha Rammohan HR, Gertz ZM, et al.Postoperative Right Ventricular Failure After Left Ventricular Assist Device Placement is Predicted by Preoperative Echocardiographic Structural, Hemodynamic, and Functional Parameters. J Card Fail. 2013 ;19:16-24.

72. Aissaoui N, Salem JE, Paluszkiewicz L, et al. Assessment of right ventricular dysfunction predictors before the implantation of a left ventricular assist device in end-stage heart failure patients using echocardiographic measures (ARVADE): Combination of left and right ventricular echocardiographic variables. Arch Cardiovasc Dis. 2015;108:300-9.

73. Kalogeropoulos AP, Al-Anbari R, Pekarek A, et al. The Right Ventricular Function After Left Ventricular Assist Device (RVF-LVAD) study: rationale and preliminary results. Eur Heart J Cardiovasc Imaging. 2016;17:429-37.

74. Cameli M, S. Bernazzali, M. Lisi, et al. Right Ventricular Longitudinal Strain and Right Ventricular Stroke Work Index in Patients With Severe Heart Failure: Left Ventricular Assist Device Suitability for Transplant Candidates. Transplant Proc. 2012;44: 2013-5.

75. Dandel M, Potapov E, Krabatsch T, et al. Load dependency of right ventricular performance is a major factor to be considered in decision making before ventricular assist device implantation. Circulation .2013;128:S14-23.

76. Kukucka M, Stepanenko A, Potapov E, et al. Right-to-left ventricular end-diastolic diameter ratio and prediction of right ventricular failure with continuous-flow left ventricular assist devices. J Heart Lung Transplant. 2011;30:64-9. 
77. Vivo RP, Cordero-Reyes AM, Qamar U, et al. Increased right-to-left ventricle diameter ratio is a strong predictor of right ventricular failure after left ventricular assist device. J Heart Lung Transplant. 2013;32:792-9.

78. Alba AC, Rao V, Ivanov J, Ross HJ, Delgado DH. Usefulness of the INTERMACS scale to predict outcomes after mechanical assist device implantation. J Heart Lung Transplant. 2009;28:827-33.

79. Wang Y, Simon MA, Bonde P, et al. Decision tree for adjuvant right ventricular support in patients receiving a left ventricular assist device. J Heart Lung Transplant. 2012;31:140-9.

80. Aissaoui A, Morshuis M, Schoenbrodt M, et al. Temporary right ventricular mechanical circulatory support for the management of right ventricular failure in critically ill patients. J Thorac Cardiovasc Surg. 2013;146:186-91.

81. Saito S, Sakaguchi T, MiyagawaS, et al. Recovery of right heart function with temporary right ventricular assist using a centrifugal pump in patients with severe biventricular failure. J Heart Lung Transplant. 2012;31:858-64.

82. Haneya A, Philipp A, Puehler T, et al.Temporary percutaneous right ventricular support using a centrifugal pump in patients with postoperative acute refractory right ventricular failure after left ventricular assist device implantation. Eur J Cardiothorac Surg. 2012;41:219-23.

\section{*Correspondence to}

Elio Aloia

Department of Medical Biotechnologies

University of Siena

Viale M. Bracci 1653100 Siena, Italy

Tel. +393473866357

E-mail: elioaloia@yahoo.it 